\title{
Comparison of Biomarkers of Neonatal Sepsis: Pro- Calcitonin Vs C- Reactive Protein
}

\author{
Angadi W.A. ${ }^{1}$, Naseem A. ${ }^{2}$ \\ ${ }^{1}$ Dr. Angadi Wasim Akram, Senior Resident, ${ }^{2}$ Dr. Altaf Naseem, Professor; both authors are affiliated with Department \\ of Pediatrics, Deccan College of Medical Sciences Hyderabad, Telangana, India.
}

Corresponding Author: Dr. Altaf Naseem, Professor, Department of Pediatrics, Deccan College of Medical Sciences Hyderabad, Telangana, India. E-mail: docaltaf@rediffmail.com,drjabeennims@gmail.com

\begin{abstract}
Background: Procalcitonin in neonatal sepsis (NS) has high sensitivity compared to C-reactive protein (CRP), but its specificity is not yet clearly defined. Objectives: Evaluation of Procalcitonin as an early marker, assessing its diagnostic utility in early-onset NS was the primary and comparing the levels of Procalcitonin with CRP was secondary objective. Method: In this observational, prospective study, neonates meeting the selection criteria were included and grouped into three, according to clinical symptoms of sepsis and blood culture. Results: Blood samples from 75 babies (male = $61.0 \%$ ) were analysed; $63.0 \%$ and $37.0 \%$ were of gestational age (GA) $\geq 37$ and $<37$ and weeks, respectively. Birthweight $<2.5 \mathrm{~kg}$ and $>2.5 \mathrm{Kg}$ was noted in $52.0 \%$ and $48.0 \%$, respectively. Meconium stained liquor ( $\mathrm{n}=34$ ), premature rupture of membranes $(n=19)$ and prolonged labour/instrumental delivery $(n=13)$ were major maternal risk factors.General $(45.33 \%)$, respiratory $(25.33 \%)$, gastrointestinal $(17.33 \%)$, cardiovascular $(6.66 \%)$ symptoms were common presentation; forty one (55.0\%) were negative for procalcitonin and $34(45.0 \%)$ were positive; $61(81.0 \%)$ tested negative for CRP, only $14(19.0 \%)$ were positive with levels $>10 \mathrm{mg} / \mathrm{mL}$. Procalcitonin positivity was statistically significant $(<0.05)$ for males, term babies and with normal birth weight favouring procalcitonin. of seven positive blood culture, coagulase positive staphylococci $(n=03)$, Klebsiella $(n=02)$, E. coli $(n=01)$, Pseudomonas $(n=01)$ were isolated. On correlation with blood culture, Procalcitonin showed better sensitivity and negative predictive value. Conclusion: Procalcitoninis a better early marker than CRP in early onset NS. It hasbetter positivity for male, term and normal birth weight babies.
\end{abstract}

Key words: Blood culture, C-reactive protein, Early marker, Negative predictive value, Neonatal sepsis, Procalcitonin.

\section{Introduction}

Neonatal sepsis (NS), a life-threatening emergency, a $3^{\text {rd }}$ major cause for mortality [1] and morbidity globally, remains a concern despite the breakthroughs in the diagnosis and management. In India, the estimated incidence of NS is 30/1000 live births contributing to $19 \%$ of all neonatal deaths [2]. The symptoms and signs of NS mimicking that of other infections, co-existence of infections make the diagnosis difficult, particularly in countries battling with infectious diseases. With varying incidence in Asian countries, and $\approx 1.6$ million neonates succumbing annually in developing countries indicates the need for an early diagnosis including clinical and laboratory evaluation[3]. There are many available markers for NS but each with limitations; Complete Blood Count (CBC), immature: total neutrophil count

Manuscript received: $25^{\text {th }}$ February 2019

Reviewed: $4^{\text {th }}$ March 2019

Author Corrected: $10^{\text {th }}$ March 2019

Accepted for Publication: $15^{\text {th }}$ March 2019
(I: T ratio) and absolute neutrophil count (ANC) do not have sensitivity especially if measured early in the course of sepsis [4]. Though culture is the gold standard for confirmation, [5] result is influenced by various factors such as prior use of antibiotics including in the prenatal period, bacterial load, laboratory standards and is time-consuming (up to 72 hours); it often fails to identify the causative organism in infected infants [6] given low culture yields.

Several leukocyte indices and acute phase protein levels were evaluated for the diagnosis of sepsis. C-reactive protein though is a classical and sensitive marker of inflammation [7] is not useful to differentiate between bacterial and other infections, has a limited role in diagnosing early-onset sepsis compelling the use of combination tests for markers [8]. In the absence of a single ideal diagnostic \& confirmatory laboratory test 


\section{Original Research Article}

[7]. the quest and search for the same for early diagnosis of NS is the need of the hour. The paradigm in pediatric practice is a neonate is likely to suffer more if the infection is under-diagnosed and untreated than over-diagnosed and treated demanding a diagnostic test with high sensitivity than high specificity.

Emerging shreds of evidence showing serum procalcitonin (PCT) as a measurable laboratory marker in the inflammatory response to the infection is promising due to its high sensitivity compared to CRP, but its specificity is still debated [9]. Considering the diversity in population, that is different from other global counterparts where the diagnostic utility of PCT is encouraging, there is a scarcity of studies on evaluation of the role of various biochemical markers in the diagnosis of NS especially PCT in Indian neonates. We attempted to document the effects of intrapartum risk factors, assess and compare the diagnostic role of Procalcitonin and CRP in early-onset NS.

\section{Materials \& Methods}

Type of study- This observational, prospective study was conducted by the Department of Pediatrics of a tertiary care teaching hospital between May 2016 and April 2017, after obtaining approval from the Institutional Ethics Committee.

Sampling method \& Sample collection- Prospective participants admitted to the neonatal intensive care unit (NICU) were identified and those meeting the selection criteria were included after obtaining written informed consent from the respective parent. Evaluation of Procalcitonin levels as an early marker in the diagnosis of neonatal sepsis and assessing its diagnostic utility in early-onset NS was the primary objective. Comparing Procalcitonin levels with CRP levels was the secondary objective of the study.

Inclusion \& Exclusion criteria- We included neonates with gestational age $>28$ weeks, birth weight $>1000$ gm and aged $<72$ hours with clinical features/risk factors of sepsis; those who were already on antibiotics, with congenital anomalies were excluded.
Maternal risk factors (fever within 2 weeks prior to delivery, prolonged rupture of amniotic membrane $>12$ $\mathrm{hr}$, foul smelling and/or meconium stained liquor, single unclean or $>3$ sterile vaginal examinations during labour, prolonged labour (sum of 1st and 2nd stage of labour $>24 \mathrm{hrs}$ ), maternal UTI within 2 weeks of delivery), neonatal history (low birth weight $(<2500$ grams but $>1000$ grams $)$, premature birth $(<37$ weeks but $>28$ weeks), perinatal asphyxia (APGAR score $<4$ at $1 \mathrm{~min}$ ) and symptoms and signs of sepsis were considered before the provisional diagnosis.

Scoring system- Gestational age was assessed by using a modified Ballard scoring system. Neonates were followed up to $72 \mathrm{hrs}$ from the time of birth for the development of symptoms and signs suggestive of neonatal sepsis. Before the initiation of antibiotic therapy in neonates suspected of sepsis, blood samples were obtained for sepsis screening on the day of admission to NICU.

According to clinical symptoms of sepsis and blood culture results, neonates were classified into three groups (fig 1).

Ethical Consideration- This study was reviewed and approved by the Institutional Ethics Committee. Prospective participants screened after obtaining a written informed consent from their respective parent.

Statistical Analysis- Using procalcitonin as a primary indicator of sepsis for the study with a sensitivity of $57 \%$, [10] Sample size calculations with alpha 0.05 and power $80 \%$ the required sample size was 67. Chisquare/ Fisher Exact test was used to find the significance of study parameters oncategorical scale between two groups. A p value $<0.05$ was considered significant.Results were presented in per cent (\%) form. Diagnostic efficiency was defined as sensitivity, specificity, positive predictive value (PPV) and negative predictive value (NPV). Statistical analysis was performed using Microsoft Excel2007 and SPSS Version 16.

\section{Results}

The blood samples from 75 babies (male $=46,61.0 \%$; female $=29,39.0 \%$ ) meeting the inclusion and exclusion criteria were analysed; twenty-eight (37.0\%), babies were born before 37 weeks of pregnancy and $47(63.0 \%)$ had a gestational age $\geq 37$ weeks. Thirty-nine (52.0\%) and $36(48.0 \%)$ babies had a birth-weight of $<2.5 \mathrm{~kg}$ and $>2.5 \mathrm{Kg}$, respectively.

Symptoms and clinical signs of sepsis included general features in 34 (45.33\%), respiratory involvement in 19 (25.33\%), gastrointestinal in $13(17.33 \%)$, cardiovascular system in five $(6.66 \%)$ and one patient each had involvement of central nervous system and haematological manifestation. 
Table-1: Laboratory investigations.

\begin{tabular}{|ll|}
\hline Parameters & $\mathbf{N}(\mathbf{\%})$ \\
\hline Total white blood cell count & $74(98.6 \%)$ \\
$>5000$ & $1(1.3 \%)$ \\
$<5000$ & \\
Absolute neutrophil count & $75(100.0 \%)$ \\
$>1800$ & 0 \\
$<1800$ & \\
Band cell ratio & $74(98.6 \%)$ \\
$<20 \%$ & $1(1.3 \%)$ \\
$>20 \%$ & \\
C-reactive protein $(\mathbf{m g} / \mathbf{m L})$ & $61(81 \%)$ \\
Negative $(<10)$ & $14(19 \%)$ \\
Positive $(>10)$ & \\
Procalcitonin $(\mathbf{n g} / \mathbf{m L})$ & $41(54.6 \%)$ \\
$<0.50$ & $13(17.3 \%)$ \\
$0.50-2.0$ & $21(28.0 \%)$ \\
$>2.0$ & \\
\hline
\end{tabular}

Forty-one $(55.0 \%)$ were negative for procalcitonin and $34(45.0 \%)$ were positive; $61(81.0 \%)$ tested negative for CRP, only $14(19.0 \%)$ were positive with levels $>10 \mathrm{mg} / \mathrm{mL}$ (Table 1$)$.

Table-2: Comparison of CRP and PCT positivity between gender, gestational age, and birth weight.

\begin{tabular}{|lllll|}
\hline Parameter & n & $\begin{array}{l}\text { CRP positive } \\
(\%)\end{array}$ & PCT positive n(\%) & p value \\
\hline $\begin{array}{l}\text { Gender } \\
\text { Male }\end{array}$ & 46 & $12(26.08 \%)$ & $23(50.0 \%)$ & 0.007 \\
$\begin{array}{l}\text { Female } \\
\text { Gestational age }\end{array}$ & 29 & $2(06.8 \%)$ & $11(37.9 \%)$ & 0.135 \\
Term & 47 & $9(19.1 \%)$ & $20(42.5 \%)$ & 0.003 \\
$\begin{array}{l}\text { Pre-term } \\
\text { Bodyweight }\end{array}$ & 28 & $5(17.8 \%)$ & $14(50.0 \%)$ & 0.326 \\
$>2.5 \mathrm{KG}$ & 36 & $8(22.2 \%)$ & $16(44.44 \%)$ & 0.000 \\
$<2.5 \mathrm{KG}$ & 39 & $6(15.3 \%)$ & $18(46.1 \%)$ & 0.387 \\
\hline
\end{tabular}

On comparing CRP and PCT positivity, the p value was found to be significant $(<0.05)$ for males, term babies and with normal birth weight (table 2).

Table-3: Association of Maternal characteristics and PCT \& CRP positivity.

\begin{tabular}{|llllll|}
\hline RISK FACTORS & N & $\begin{array}{l}\text { PCT } \\
\text { Positive n }(\%)\end{array}$ & p value & $\begin{array}{l}\text { CRP } \\
\text { Positive } \\
(\%)\end{array}$ & n value \\
\hline Meconium Stained Liquor & 34 & $15(44.11 \%)$ & 0.847 & $04(11.7 \%)$ & 0.236 \\
PROM & 19 & $8(42.1)$ & 0.744 & $04(21.05 \%)$ & 0.743 \\
Prolonged labour or Instrumental & 13 & $4(30.7 \%)$ & 0.246 & $03(23.07 \%)$ & 0.699 \\
delivery & & & & & 1.000 \\
Maternal UTI & 1 & $1(100 \%)$ & 0.451 & 0 & 0.232 \\
$>$ 3 Vaginal Examination & 5 & $4(80.0 \%)$ & 0.170 & $2(40.0 \%)$ & 0.187 \\
rupture of membrane & 5 & $1(100 \%)$ & 0.453 & $1(100.0 \%)$ & 1.000 \\
Foul smelling Liquor & 1 & $1(50.0 \%)$ & 1.000 & 0 & NA \\
Intrapartum fever $\left(>38^{\circ} \mathrm{F}\right)$ & 2 & 0 & NA & 0 & \\
Maternal Infections & 0 & & & & \\
\hline
\end{tabular}


Original Research Article

Table-4: Evaluation of Procalcitonin in relation to CRP.

\begin{tabular}{|lllllll|}
\hline Parameters & $\begin{array}{l}\text { PCT in relation } \\
\text { positivity }\end{array}$ & to & $\begin{array}{l}\text { CRP in realtion to } \\
\text { positivity }\end{array}$ & PCT \\
\hline True positive (n) & 12 & 12 & & \\
False positive (n) & 22 & 2 & & \\
False negative (n) & 2 & 22 & & \\
True negative (n) & 39 & 39 & & \\
Sensitivity \% & $85.7 \%$ & $35.2 \%$ & & \\
Specificity \% & $63.9 \%$ & $95.1 \%$ & & \\
PPV \% & $35.2 \%$ & $85.7 \%$ & & \\
NPV \% & $95.1 \%$ & $63.9 \%$ & & \\
\hline
\end{tabular}

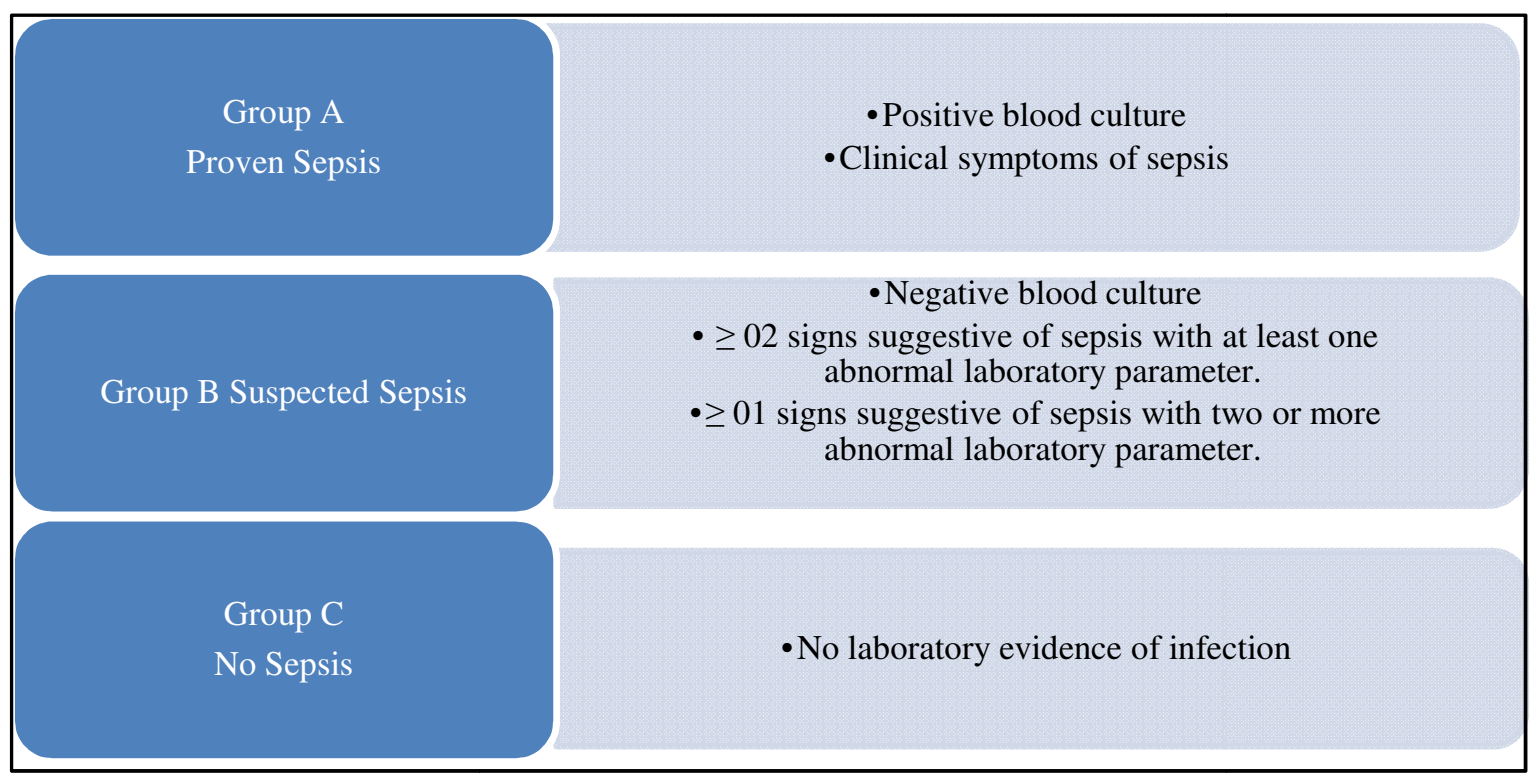

Figure-1: Study groups

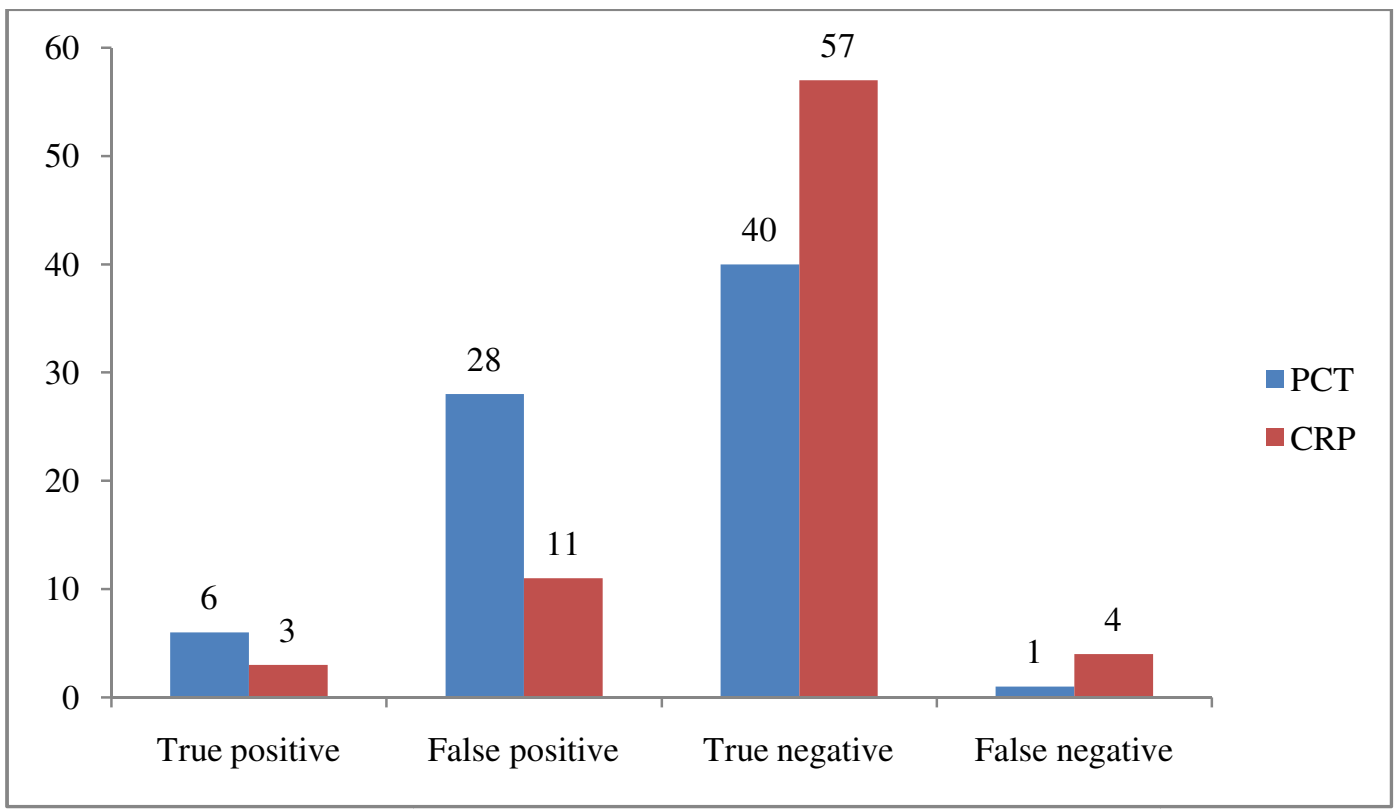

Figure 2: Comparison of true $\&$ false positivity, true $\&$ false negativity of CRP and PCT 
Original Research Article

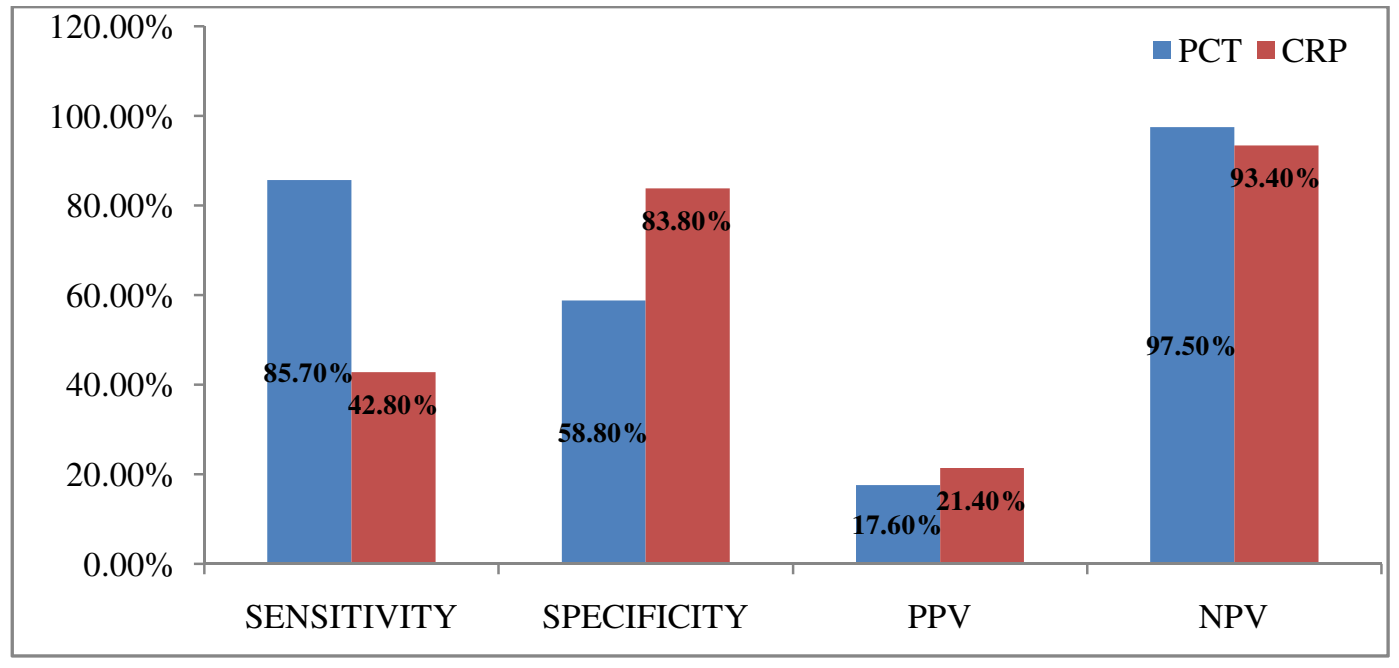

Figure 3: Correlation of Procalcitonin, CRP to blood culture

Meconium stained liquor $(n=34)$, premature rupture of membranes $(\mathrm{PROM})(\mathrm{n}=19)$ and prolonged labour/instrumental delivery $(\mathrm{n}=13)$ were the major maternal risk factors observed in our study (Table 3 ).

Blood culture: Only seven (9.0\%) had positive blood culture; coagulase positive staphylococci ( $n=03,04 \%)$, Klebsiella $(n=02,2.6 \%)$, E. coli $(n=01,1.3 \%)$, Pseudomonas growth $(n=01,1.3 \%)$ were grown on culture. Sixty eight $(91.0 \%)$ cultures showed no growth.

There was no proven sepsis in $38(50.6 \%)$, suspected sepsis in $30(40 \%)$ and proven sepsis in $7(9.3 \%)$ cases.

Procalcitonin in comparison with CRP showed better sensitivity and negative predictive value (Figure 3 and Table 4).

\section{Discussion}

The causes for sepsis differ in early and late onset neonatal sepsis; while maternal factors are the root cause in the former, environmental contribution (catheters, indwelling lines, contact with an infected caregiver) is significant in the latter. Early diagnosis along with the identification of the cause is crucial in the management but often is most challenging. Hence, neonates with risk factors for infection or clinical suspicion of infection are empirically treated with antibiotics, because the mortality rate of untreated sepsis can be as high as $50 \%$. [11] An early sensitive and specific laboratory test would be helpful to guide clinicians in neonatal units in deciding whether or not to start antibiotics and avoid the unnecessary treatment of non-infected patients.

CRP It has been found to have better specificity and PPV in late-onset sepsis. This improved accuracy is because CRP lags after the onset of infection because transcription of this protein is under the direction of other cytokines [12]. CRP is considered ideal biomarker as it's level remain elevated till the infection resolves. Elevated levels can be seen within 4-6 hours of the onset that reaches the abnormal levels in $<24$ hours of infection; peak levels are reached within 2-3 days of infection, and most importantly, remain elevated till the infection is cleared. Procalcitonin being more sensitive than CRP particularly during the first 24 hours of birth [13] and in bacterial infection is being considered in the initial battery of investigations. While bacterial culture time consuming, estimation of procalcitonin requires much less turnaround time (90-120 mins), reducing the much crucial waiting time [13-14]. However, raised Procalcitonin levels are seen after 24 hours after the onset of infection, associated with other respiratory diseases, and in those born to diabetic mothers, a cautious approach is needed in interpreting the results.

Of these two markers, procalcitonin scored better in comparison to CRP as an early diagnostic marker [1516]. With insufficient data, it becomes necessary to evaluate the importance of Procalcitonin as an early marker and the need to include this investigation in Sepsis Screen for the newborn.

Previous studies have thrown light the reliability of procalcitonin in the diagnosis of neonatal sepsis, particularly in distinguishing causative agents, proving its value in excluding bacterial infections, with a negative predictive value of $93 \%$ [17-18]. 


\section{Original Research Article}

Demographically, male children $(61.3 \%)$ were more affected in our study, similar to the available reports (62.4\%-65.9\%) [19-21]. There is a genetic linking to the $\mathrm{x}$-linked immuno-regulatory gene resulting in the host's susceptibility to the infection in males [22]. Available literature [23] undoubtedly indicates that low birth weight babies are more prone to develop neonatal sepsis $(54.5 \%-66.0 \%)[19,24]$ due to immature physiological and immunological functions and maternal risks. Our study is in support of this observation as $53.0 \%$ of babies had a birth weight of $<2.5 \mathrm{Kg}$. Apart from maternal infection, and premature rupture of membranes low birth-weight $(<2.5 \mathrm{Kg})$ and gestational age $(<37$ weeks as low as $<30$ weeks) were considered risk factors for neonatal sepsis. [25-27]. An inverse relationship has been documented between gestational age $(\leq 30$ weeks) and low birth weight $(\leq 1500$ gms $)$ with late-onset neonatal sepsis [28]. In contrast, $66.2 \%$ had a gestational age of $\geq 37$ weeks; similar observations were reported by other Indian authors $[16,20]$.

Premature rupture of membranes, meconium stained and/foul smelling liquor, prolonged labour/instrumental delivery, >three vaginal examinations after the rupture of the membranes, intra-partal fever and maternal infections including UTI are the common risk factors reported [20,22,29-31] Meconium stained liquor (45.3\%), PROM (25.3\%), prolonged labor/instrumental delivery $(173 \%)$ were common risk factors in our study.

Clinical features and the further course in neonatal sepsis depends on various factors such as birth weight, place of delivery, the age of newborn, intervention in preventable factors for sepsis, availability, accessibility, affordability and timely referral of baby to an appropriate centre. Clinical features of NS vary, often indistinguishable from other common infections. General symptoms such as refusal of feed, respiratory symptoms \& signs, fever, bleeding manifestation, jaundice, alteration in body temperature, seizures, hypotonia are the clinical presentations. We report respiratory signs and symptoms (56\%), followed by general symptoms like refusal to feed, lethargy (26.6\%). Tachypnea/respiratory distress (75\%), refusal to feeds $(74 \%)$, and fever $(69 \%)$ were reported by Kinchi et al [21].

In our study, $98.6 \%$ had $>5000$ cells $/ \mathrm{mm}^{3}$, absolute neutrophil count was $>1800$ cells $/ \mathrm{mm}^{3}$ in all $(100 \%)$, band cell ratio $<20 \%$ was seen in $98.6 \%$,

Culture is the standard guide for the administration of antibiotics but is time-consuming and isolating the causative organism is not always possible. The success of isolating bacterial pathogens from blood depends upon the quantum of blood, frequency of culture, duration of incubation. In our study, $90.6 \%$ had negative blood culture, and only seven $(9.3 \%)$ were culture positive, similar to previous studies $(0.8 \%-9 \%)$ [31, 32-35]. Coagulase positive staphylococcal growth (04\%), Klebsiella (2.6\%), E. coli growth, and Pseudomonas growth was observed in $1.3 \%$ each, respectively, in our study, similar to previous studies [31, 33-36]. The bacteriological profile from blood cultures of neonates in a tertiary care hospital revealed that Staphylococci and Klebsiella were the most common isolates; Gram-positive and Gram-negative organisms together accounted for $32.3 \%$ (266/823) and $33.8 \%(278 / 823)$ of the isolates, respectively [37]. Previous studies have isolated group B streptococci, Staphylococcus species, E.coli, Klebsiella, enterobacter.

In our study, at a cut off value of $>10 \mathrm{mg} / \mathrm{L}$ the CRP, sensitivity was $42.8 \%$, specificity of $83.8 \%$, PPV was $21.4 \%$ and NPV of $93.4 \%$, similar to the observations of Joram et al [38]. These results were also comparable to those by Abdollahi et al [39] who reported lower sensitivity (69\%) and higher specificity (96\%) of CRP in detecting sepsis. Bonac et al [40] compared the levels of CRP, PCT and IL- 6 in the diagnosis of neonatal sepsis in 58 infants. They reported that the sensitivity, specificity, PPV and NPV of CRP at the time of diagnosis was $36 \%, 92 \%, 43 \%$ and $89 \%$ respectively using a cut off value of $14 \mathrm{mg} / \mathrm{l}$ which is closer to the present study.

In our study, procalcitonin showed a sensitivity of $85.7 \%$, specificity of $58.8 \%$, PPV of $17.6 \%$ and NPV of $97.5 \%$ which was similar to the reports by Joram et al[38] Our study showed that sensitivity of PCT for the diagnosis of neonatal sepsis is higher $(85.7 \%)$ than that ofCRP (42.8\%) using a cut off value of $0.5 \mathrm{ng} / \mathrm{ml}$ and $10 \mathrm{mg} / \mathrm{L}$ for PCT and CRP, respectively. The higher sensitivity of PCT in comparison to CRP was also reported in the literature [41-42]. At the same cut off values, we found that the specificity of PCT $(58.8 \%)$ to be lower than that of CRP (83.8\%) in different studies [41,43] and higher in others. [42] Our study supports the observation that PCT is more sensitive than CRP in the detection of neonatalsepsis. Serum procalcitonin has shown to be superior to serum CRP level concerning an early diagnosis of NS, in detecting the severity of the illness and evaluation of the response to the antibiotic treatment [44]. However, when combined, these tests will help the pediatrician in 'ruling out' in negative PCT test and "ruling in" the possibility of sepsis with a raised CRP [34] 
Our study indicates that PCT is a better predictor of sepsis in males, for term babies and with a normal birth weight indicating and hence, a better marker in this population. However, in contrary, Fendleret al [45] found only PCT as a valuable tool after comparing the diagnostic usefulness of PCT, CRP and I: T in nosocomial sepsis among preterm neonates. Lachowskaetal. [46] in their study on the usefulness of PCT as a marker of early-onset systemic infections in preterm newborns concluded that in such cases PCT had significantly greater values than uninfected ones $(p<0.005)$. Further studies are required to demonstrate the influence of gender, gestational age and birth weight in a larger population.

We suggest that the commencement of antibiotics in newborn infants must be based on the PC Tresults on the day of their admission to the NICU. The considerable heterogeneity of the results among the studies evaluating different markers for detection of neonatal sepsis can be explained by the lack of a universally acceptable definition of neonatal sepsis, a difference in the cut-off values incorporated in the studies and organism involvedin the sepsis that all may interfere in results.

Laboratory investigations are helpful in establishing and confirming the clinical diagnosis [47] Leukopenia is an important indicator of underlying infection as these neonates have a limited bone marrow reserve; the absolute neutrophil count is a more specific indicator of sepsis than the total white blood counts. A ratio of immature to total neutrophils $>0.2$ is reported as a better indicator of neonatal sepsis. It is included in the initial list of investigations in the initial days of life in suspected sepsis. It has the limitation of moderate sensitivity but has good negative predictive value. Other markers were having moderate sensitivity though direct towards diagnosis (Erythrocyte sedimentation rate, cytokines and interleukins (IL-6, IL-8, CD 11b)[48] but are not confirmative [49] IL-6 is reported to be a sensitive and specific indicator for the diagnosis of the NS due to PROM [49]. CRP and procalcitonin though are more specific there is no single confirmatory test; hence, a panel of test that includes haematological, biochemical assays, culture (blood, urine and cerebrospinal fluid) \& sensitivity and radiological evaluation (chest, abdomen) is recommended. Assessment of antigen levels, virological tests will prove its worth in difficult to diagnose cases.

Of the biomarkers, CRP a well-proven biomarker, procalcitonin an emerging strong, promising candidate, have nicked their place in the diagnosis of neonatal sepsis. However, recent research indicates the procalcitonin /CRP ratio is a better indicator to differentiate proven from the suspected sepsis cases [50]. Besides, procalcitonin-guided therapy has advantages such as lesser duration of antibiotic administration, fewer cases of re-infection and no death attributable to sepsis. However, there is less evidence in the Indian population, requiring further studies to confirm [51].

\section{Conclusion}

PCT is a better early marker of sepsis than CRP in early onset NS. It has s better positivity for males, term and normal birth weight babies. Meconium stained liquor, PROM, prolonged labor/instrumental delivery were common risk factors. Procalcitonin having a higher negative predictive value can be used in ruling out NS. Including procalcitonin in the regular panel of investigations will prove beneficial in early detection.

What this study adds to existing knowledge- PCT is more reliable method of diagnosing neonatal sepsis because it showed better sensitivity and negative predictive value as compared to CRP therefore helps in detection of most number of cases and decrease in number of patients treated unnecessarily.

PCT is a better early marker of sepsis, helps in avoiding antibiotic therapy where it is not required and thereby reducing the cost of therapy and also the emergence of bacterial resistance.

\section{Author Contribution}

- Dr Angadi Wasim Akram contributed to the conduct of the study, study assessments, data collection, statistical analysis, and manuscript preparation.

- Dr Altaf Hussain contributed to the study design \& approved the study protocol, reviewed the statistical analysis \& interpretation of the analysis, reviewed and approved the manuscript

Acknowledgement: Authors thank Dr M S Latha for writing assistance.

Funding: Nil, Conflict of interest: None initiated, Perission from IRB: Yes

\section{References}

1. Liu L, Johnson HL, Cousens S, Perin J, Scott S, Lawn JEet al. Global, regional, and national causes of child mortality: an updated systematic analysis for 2010 with time trends since 2000. Lancet. 2012; 379 (9832): 2151-61. doi: 10.1016/S0140-6736(12) 60560-1. 


\section{Original Research Article}

2. National Neonatal Perinatal Database. Report 200203. Published by NNPD Nodal Centre, Department of Pediatrics, All India Institute of Medical Science, New Delhi. Available from http://www.newbornwhocc.org/ pdf/nnpd_report_2002-03. PDF last accessed 22 February 2019.

3. Vergnano S, Sharland M, Kazembe P, et al. Neonatal sepsis: an international perspective. Arch Dis Child Fetal Neonatal Ed. 2005 May; 90(3): F220-4. DOI:10. $1136 /$ adc. 2002.022863

4. Da Silva O, Ohlsson A, Kenyon C. Accuracy of leukocyte indices and $\mathrm{C}$-reactive protein for diagnosis of neonatal sepsis: a critical review. Pediatr Infect Dis J. 1995 May;14(5):362-6.

5. Camacho-Gonzalez A, Spearman PW, Stoll BJ. Neonatal infectious diseases: evaluation of neonatal sepsis. Pediatr Clin North Am. 2013 Apr;60(2): 36789. doi: 10. 1016/j.pcl.2012. 12.003. Epub 2013 Jan 17.

6. Squire E, Favara B, Todd J. Diagnosis of neonatal bacterial infection: hematologic and pathologic findings in fatal and nonfatal cases. Pediatrics. 1979 Jul; 64 (1): 60-4.

7. Chauhan SB, Vaghasia V, Chauhan BB. C-reactive protein (crp) in early diagnosis of neonatal septicemia. National Journal of Medical Research 2012; 2 (3): 276-78.

8. Lakhey, A., \& Shakya, H. Role of Sepsis Screening in early diagnosis of Neonatal Sepsis. Journal of Pathology of Nepal, 2017;7(1):1103-10. https://oi.org /10. 3126/jpn.v7i1.16944.

9. Pontrelli G, De Crescenzo F, Buzzetti R, Jenkner A, Balduzzi S, et al. Accuracy of serum procalcitonin for the diagnosis of sepsis in neonates and children with systemic inflammatory syndrome: A meta-analysis. BMC Infect Dis.2017;17(1):302. doi: 10.1186/s12879017-2396-7.

10. Indino P1, Lemarchand P, Bady $\mathrm{P}$, de Torrenté A, Genné L, Genné D. Prospective study on procalcitonin and other systemic markers in patients with Leucocytosis. International J Infect Dis 2008; 12(3): 319-24.

11. Angus DC, Wax RS. Epidemiology of sepsis: an update. Crit Care Med. 2001 Jul; 29 (7 Suppl): S109-16.
12. Benitz WE, Han MY, Madan A, et al. Serial serum C-reactive protein levels in the diagnosis of neonatal infection. Pediatrics. 1998 Oct;102(4):E41.

13. Altunhan $\mathrm{H}$, Annagür A, Örs R, Mehmetoğlu I. Procalcitonin measurement at 24 hours of age may be helpful in the prompt diagnosis of early-onset neonatal sepsis. Int J Infect Dis. 2011 Dec; 15 (12):e 854-8. doi: 10. 1016/j. ijid. 2011. 09.007. Epub 2011 Oct 22 .

14. Meem M, Modak JK, Mortuza R, et al. Biomarkers for diagnosis of neonatal infections: A systematic analysis of their potential as a point-of-care diagnostics. J Glob Health. 2011 Dec;1(2):201-9.

15. Ali AM, Moaz MA, Ghoniem E, et al. Reliability of serum procalcitonin concentrations for the diagnosis of sepsis in neonates. Egypt J Immunol. 2008;15(1):75-84.

16. Sucilathangam G, Amuthavalli K, Velvizhi G, Ashihabegum MA, Jeyamurugan T, Palaniappan N. Early Diagnostic Markers for Neonatal Sepsis: Comparing Procalcitonin (PCT) and C-Reactive Protein (CRP). Journal of clinical and diagnostic research 2012; 6: 627-631.

17. Guibourdenche J, Bedu A, Petzold L, et al. Biochemical markers of neonatal sepsis: value of procalcitonin in the emergency setting. Ann Clin Biochem. 2002 Mar; 39 (Pt 2): 130-5. DOI:10.1258/ 0004563021901874

18. Ballot DE, Perovic O, Galpin J, et al. Serum procalcitonin as an early marker of neonatal sepsis. $\mathrm{S}$ Afr Med J. 2004 Oct;94(10):851-4.

19. Mehar, V, Agarwal S, Singh R, Agarwal A, Agrawal N, Majethia A. Relationship between gestational age and mode of delivery with neonatal septicemia. International Journal of Contemporary Pediatrics,2016;3(3): 891-95. DOI: http://dx.doi.org/10. 18203/2349-3291.ijcp20162361

20. Tallur SS, Kasturi AV, Nadgir SD, et al. Clinicobacteriological study of neonatal septicemia in Hubli. Indian J Pediatr. 2000 Mar;67(3):169-74.

21. Kinchi YR, Kumar A,Yadav S. Profile of Neonatal sepsis. J Coll Med Sci Nepal 2010;6(2):1-6. https:// doi.org/ 10.3126/jcmsn.v6i2.3609

22. Chacko B, Sohi I. Early onset neonatal sepsis. Indian J Pediatr. 2005 Jan;72(1):23-6. 


\section{Original Research Article}

23. Gallegher PG. Sepsis Neonatorum. In: Mc Millan JA, De Angelis C, Jones MD. OskisPediatrics Merck Manual; 2005.

24. Malik A, Hasani SE, Khan HM, et al. Nosocomial infections in newborns. Indian Pediatr. 2001 Jan;38(1): 68-71.

25. Pérez RO, Lona JC, Quiles M, et al. [Early neonatal sepsis, incidence and associated risk factors in a public hospital in western Mexico]. Rev ChilenaInfectol. 2015 Aug;32(4):387-92. doi: 10.4067/S0716-10182015000 500003 .

26. Salem SY, Sheiner E, Zmora E, et al. Risk factors for early neonatal sepsis. Arch Gynecol Obstet. 2006 Jul;274(4):198-202. Epub 2006 Feb 21. DOI:10.1007/s 00404-006-0135-1

27. Tapia-Rombo CA, Cortés-Sauza J, Saucedo-Zavala VJ, Cuevas-Urióstegui ML. Predisposing risk factors that participate in neonatal sepsis mortality rate. Gac Med Mex. 2006;142(4):283-9.[article in Spanish]

28. Haque KN, Khan MA, Kerry S, et al. Pattern of culture-proven neonatal sepsis in a district general hospital in the United Kingdom. Infect Control Hosp Epidemiol. 2004 Sep; 25 (9):759-64. DOI: 10.1086/ 502473

29. Raghavan M, Mondal GP, Bhat BV, et al. Perinatal risk factors in neonatal infections. Indian $\mathrm{J}$ Pediatr. 1992 May-Jun;59(3):335-40.

30. Kuruvilla KA, Pillai S, Jesudason M, et al. Bacterial profile of sepsis in a neonatal unit in south India. Indian Pediatr. 1998 Sep;35(9):851-8.

31. Mathai E, Christopher U, Mathai M, et al. Is Creactive protein level useful in differentiating infected from uninfected neonates among those at risk of infection? Indian Pediatr. 2004 Sep;41(9):895-900.

32. Boyle RJ, Chandler BD, Stonestreet BS, et al. Early identification of sepsis in infants with respiratory distress. Pediatrics. 1978 Nov;62(5):744-50.

33. Rodwell RL, Anton LL, David IT. Early diagnosis of Neonatal sepsis using a haematological scoring system. J Pediatr 1987; 112(5): 761-7.

34. Roy I, Jain A, Kumar M, et al. Bacteriology of neonatal septicaemia in a tertiary care hospital of northern India. Indian J Med Microbiol. 2002 Jul-Sep; 20 (3):156-9.
35. Ahmed AS, Chowdhury MA, Hoque M, et al. Clinical and bacteriological profile of neonatal septicemia in a tertiary level pediatric hospital in Bangladesh. Indian Pediatr. 2002 Nov; 39 (11): 1034-9.

36. Karthikeyan G, Premkumar K. Neonatal sepsis: Staphylococcus aureus as the predominant pathogen. Indian J Pediatr. 2001 Aug; 68 (8):715-7.

37. Kumhar GD, Ramachandran VG, Gupta P. Bacteriological analysis of blood culture isolates from neonates in a tertiary care hospital in India. J Health Popul Nutr. 2002 Dec;20(4):343-7.

38. Joram N, Boschar C, Denizot S, V Loubersac, N Winer, J C Rose et al. Umbilical cord blood procalcitonin and $\mathrm{C}$ reactive protein concentrations as markers for early diagnosis of very early-onset neonatal infection. Arch Dis Child Fetal Neonatal Ed. 2006; 91 (1) : 65-6.

39. Abdollahi A1, Shoar S, Nayyeri F, et al. Diagnostic Value of Simultaneous Measurement of Procalcitonin, Interleukin-6 and hs-CRP in Prediction of Early-Onset Neonatal Sepsis. Mediterr J Hematol Infect Dis. 2012; 4(1): e2012028. doi: 10. 4084/MJHID. 2012. 028. Epub 2012 May 6.

40. Bonac B, Derganc M, Wraber B, et al. Interleukin-8 and procalcitonin in early diagnosis of early severe bacterial infection in critically ill neonates. Pflugers Arch. 2000;440(5 Suppl):R72-4.

41. Naher BS, Mannan MA, Noor K, et al. Role of serum procalcitonin and $\mathrm{C}$-reactive protein in the diagnosis of neonatal sepsis. Bangladesh Med Res Counc Bull. 2011 Aug;37(2):40-6.

42. Vazzalwar R, Pina-Rodrigues E, Puppala BL, et al. Procalcitonin as a screening test for late-onset sepsis in preterm very low birth weight infants. J Perinatol. 2005 Jun; 25(6):397-402.

43. Janota J, Stranák Z, Bělohlávková S, et al. Postnatal increase of procalcitonin in premature newborns is enhanced by chorioamnionitis and neonatal sepsis. Eur J Clin Invest. 2001 Nov;31(11):978-83.

44. Köksal N, Harmanci R, Cetinkaya M, et al. Role of procalcitonin and CRP in diagnosis and follow-up of neonatal sepsis.Turk J Pediatr. 2007 Jan-Mar; 49 (1): 21-9 


\section{Original Research Article}

45. Fendler WM, Piotrowski AJ. Procalcitonin in the early diagnosis of nosocomial sepsis in preterm neonates. J Paediatr Child Health. 2008 Mar;44(3):1148. Epub 2007 Oct 10. DOI:10.1111/j.1440-1754.2007. 01230.x

46. Lachowska M, Gajewska E. Usefulness of procalcitonin (PCT) as a marker of early-onset systemic infections in preterm newborns. Med Sci Monit. 2004; 10 (Suppl 2): 33-5.

47. Baltimore RS. Neonatal sepsis: epidemiology and management. Paediatr Drugs. 2003;5(11):723-40. DOI: 10. 2165/00148581-200305110-00002

48. Chauhan N, Tiwari S, Jain U. Potential biomarkers for effective screening of neonatal sepsis infections: An overview. Microb Pathog. 2017;107:234-42. doi: 10. 1016/j. micpath. 2017.03.042.
49. Qiu $\mathrm{X}^{1}$, Zhang $\mathrm{L}^{1}$, Tong $\mathrm{Y}$, et al. Interleukin-6 for early diagnosis of neonatal sepsis with premature rupture of the membranes: A meta-analysis. Medicine (Baltimore). 2018Nov;97(47):e13146. doi:10. 1097 / MD.0000000000013146.

50. Hahn WH, Song JH, Kim H, et al. Is procalcitonin to $\mathrm{C}$-reactive protein ratio useful for the detection of late onset neonatal sepsis? J MaternFetal Neonatal Med. 2018 Mar;31(6):822-826. doi:10.1080/ 14767058. 2017.1297410. Epub 2017 Mar 9.

51. Stocker M, van Herk W, El Helou S, et al. Procalcitonin-guided decision making for duration of antibiotic therapy in neonates with suspected earlyonset sepsis: a multicentre, randomised controlled trial (NeoPIns). Lancet. 2017 Aug 26;390(10097):871-881. doi: 10.1016/ S0140-6736 (17) 31444-7. Epub 2017 Jul 12.

\section{How to cite this article?}

Angadi W. A, Naseem A. Comparison of Biomarkers of Neonatal Sepsis: Pro- Calcitonin Vs C-Reactive Protein. Int J Pediatr Res. 2019;6(03):134-143.doi:10.17511/ijpr.2019.i03.06 